\title{
Research on hot air ice melt system for cable sheaths of Er'qi Yangtze River Bridge
}

\author{
Liu Qianqian ${ }^{1 *}$, Han yongtao ${ }^{1}$, and Fan xueliang ${ }^{1}$ \\ ( ${ }^{1}$ China Railway Wuhan Survey and Design Co., Ltd., Wuhan 430070, China)
}

\begin{abstract}
To prevent the cable sheaths of Er'qi Yangtze River Bridge from freezing under bad weather in winter, which may lead to ice fall and bring traffic safety accidents, a theoretical model and technical scheme of hot air ice melt system for Er'qi Yangtze River Bridge has been proposed. Based on the established heat transfer model for cable sheaths, the characteristics of heat transfer between internal hot air and outdoor environment have been analyzed. Under the condition when the temperature of the end of cable sheath's outwall is more than $3{ }^{\circ} \mathrm{C}$, the range of temperature and speed of input hot air were estimated, which provides a theoretical basis for hot air melt system for cable-stayed bridge sheaths.
\end{abstract}

\section{Introduction}

In recent years, our country's bridge construction has been developed rapidly. The cable-stayed bridge is widely built in crossing the river due to its beautiful shape and convenient construction. However, in the middle and lower reaches of the Yangtze River, there is continuous low temperature rain and snow in winter, and recent years, some cable stayed bridges appeared freeze and ice fall. In 2015, the ice fell from Tianxingzhou Bridge in Wuhan. In January of 2018, the cables of the Poyang Lake Bridge has been frozen, and in February, the ice of Anqing Yangtze River Bridge's tower cables melted and fell to the cars on the bridge; In January of 2019, the Er'qi Yangtze River Bridge and the Baishazhou Bridge in Wuhan also appeared freeze and then ice melt with fall. The cable sheaths of cable-stayed bridge were frozen with ice fall posed detrimental effect on traffic safety accidents and caused certain social negative influence.

\section{Research review of ice melt system for cable sheaths}

The cable sheaths of cable-stayed bridge froze was a relatively low probability phenomenon under bad weather in winter, only when multiple negative meteorological factors appear at the same time. The solution of this problem is still in the experimental research stage at home and abroad, and no mature engineering technical measures have been applied to practical projects. In previous studies on the cable deicing and melting system mainly has the following directions: the First is to use the thermal resistance material to heat the cable sheaths to deicing ${ }^{[1]}$; The second is to use high temperature air to heat the cable sheaths ${ }^{[2]}$.
The third is to brush hydrophobic paint on the outside of the cable sheaths. The Fourth is use of physical and mechanical deicing devices ${ }^{[3]}$. This paper attempts to take Er'qi Yangtze River bridge as the research object to demonstrate the feasibility of the method of heating cable sheath with hot air.

The Er'qi Yangtze River Bridge is a cable-stayed bridge, has a main span of $2 \times 616 \mathrm{~m}$ from three concrete towers, the width of deck is $30.5 \mathrm{~m}$ and the height of the main tower is $205 \mathrm{~m}$ with two opposing 8 lanes of traffic. The cable of the bridge was built by parallel steel strand, the cable is composed of multiple unbonded high strength parallel galvanized steel strand, and the outer layer is equipped with HDPE sheath. There are 264 cables in total, the maximum length of a single cable is $300 \mathrm{~m}$, and each cable is equipped with HDPE De250 protective sheath.

\section{Parameter of cable sheaths model}

In this paper, the model of conveying the hot air to heat cable sheath is analyzed, that is deliverying the hot air from one end of the cable sheath to the other end to keep the temperature of the cable sheath out wall higher than the freezing point of water, and prevent the sheath from freezing. The parameters of single cable sheath model is presented in Tab.1.

Tab.1 The parameters of single cable sheath model

\begin{tabular}{cccc}
\hline Project & Symbol & Value & Unit \\
\hline $\begin{array}{c}\text { External diameter of } \\
\text { cable sheath }\end{array}$ & $D_{2}$ & 0.25 & $\mathrm{~m}$ \\
$\begin{array}{c}\text { Thicknesses of cable } \\
\text { sheath }\end{array}$ & $\sigma$ & 0.008 & $\mathrm{~m}$ \\
$\begin{array}{c}\text { Internal diameter of } \\
\text { cable sheath }\end{array}$ & $D_{1}$ & 0.234 & $\mathrm{~m}$ \\
$\begin{array}{c}\text { Net area of cable sheath } \\
\text { (steel strand is deducted) }\end{array}$ & $\mathrm{A}$ & 0.032 & $\mathrm{~m}^{2}$ \\
\hline
\end{tabular}

$\overline{{ }^{*} \text { Corresponding author: queenaliu0608 } @ 163 . c o m}$ 


\begin{tabular}{cccc}
\hline Project & Symbol & Value & Unit \\
\hline $\begin{array}{c}\text { Thermal conductivity of } \\
\text { cable sheath }\end{array}$ & $\lambda_{1}$ & 0.5 & $\mathrm{~W} /(\mathrm{m} \cdot \mathrm{K})$ \\
Length of cable & $l$ & 300 & $\mathrm{~m}$ \\
\hline
\end{tabular}

The meteorological parameter on February 11, 2019, which the weather of the day that ice fall occurred on the Er'qi yangtze river bridge in Wuhan, was used as a reference. The weather on February 11, 2019 was sleet and rainy, during this period, the maximum wind force was level 3-4 from the north, and the wind speed was about $3.4-7.9 \mathrm{~m} / \mathrm{s}$. The minimum temperature at night was $-1{ }^{\circ} \mathrm{C}$, and the maximum temperature in the day was $3^{\circ} \mathrm{C}$. Considering the changes of river wind speed and air temperature comprehensively, the outdoor meteorological parameters and conditions are shown in Tab.2.

Tab.2 The outdoor meteorological parameter

\begin{tabular}{cccc}
\hline Project & Symbol & Value & Unit \\
\hline Air temperature & $T_{w}$ & -3 & ${ }^{\circ} \mathrm{C}$ \\
Wind speed & $v_{2}$ & 5 & $\mathrm{~m} / \mathrm{s}$ \\
Density & $\rho_{2}$ & 1.293 & $\mathrm{~kg} / \mathrm{m}^{3}$ \\
Specific heat capacity & $c_{p 2}$ & 1005 & $\mathrm{~J} /(\mathrm{kg} \cdot \mathrm{K})$ \\
Thermal conductivity & $\lambda_{2}$ & 0.0244 & $\mathrm{~W} /(\mathrm{m} \cdot \mathrm{K})$ \\
\hline
\end{tabular}

\section{Thermodynamic calculation of heat transfer model for cable sheath}

Based on the calculation of Reynolds number, the heat transfer of the cable sheath for cable-stayed bridge is divided in three processes, that is the turbulent convection heat transfer between the hot air inside the sheath and the inner wall of the sheath, thermal conduction heat transfer between the inner wall and the outer wall of the sheath, and forced convection heat transfer between the outer wall of the sheath and the air outside the sheath. The heat transfer capacity above-mentioned are $\varphi_{1}, \varphi_{2}, \varphi_{3}$ respectively. The total heat transfer between the hot air inside the sheath and the outdoor air is $Q_{1}$, and the heat transfer $Q_{2}$, sent by the hot air into the sheath. According to the law of energy conservation, $\varphi_{1}=\varphi_{2}=\varphi_{3}=Q_{1}=Q_{2}$ 。

To simplify the model, when the steel cable inside the sheath and the hot air reach thermal balance, there is no more heat transfer between the two, so the heat exchange between the steel cable and the hot air can be ignored.

To prevent the cable sheath from freezing, the end temperature of the outer wall of the sheath $t_{\mathrm{b}}^{\prime}$ should be kept at $t_{b}^{\prime} \geq 3^{\circ} \mathrm{C}$,so the hot air's inlet temperature $t_{1}$ and wind speed $v_{1}$ of entering the sheath was calculated and analyzed. The thermally physical properties of the fluid (specific heat capacity $C_{p}$, thermal conductivity $\lambda$, density $\rho$ ) are related to the fluid temperature, due to the cable structure and melting point of the cable sheath on the cable-stayed bridge, and the hot air inlet temperature should be considered at $\mathrm{t}_{1} \leq 60^{\circ} \mathrm{C}$.
(1) When the outer wall temperature of the end of sheatht $t_{b}^{\prime} \geq 3^{\circ} \mathrm{C}$, the outlet temperature of hot air input from the sheath is calculated as $t_{2}$.

$$
R e=\frac{\rho_{2} v_{2} D_{2}}{\mu}
$$

$\mathrm{Re}=92248$,the flow state is turbulent;

In the above formula, $\rho_{2} 、 \mathrm{v}_{2}$ are presented in Tab. 2; $\mathrm{D}_{2}$ is presented in Tab. $1 ; \mu$ is defined as Aerodynamic viscosity, Pa. S。

$$
\operatorname{Pr}=\mu c_{p 2} / \lambda_{2}
$$

In the above formula, $\mathrm{c}_{\mathrm{p} 2} 、 \lambda_{2}$ are presented in Tab.2;

$$
N u=0.266 R_{e}^{0.805} \operatorname{Pr}^{1 / 3}
$$

Convection coefficient between the out wall of sheath and the air is $h_{2}$.

$$
h_{2}=N u \lambda_{2} / D_{2}
$$

The convection heat transfer of cold air across the outer wall of sheath [4].

$$
\varphi_{3}=A h_{2} \Delta t_{2}=32.9 \mathrm{~kW}
$$

Based on the law of conservation of energy, $\varphi_{3}=\varphi_{2}$, so the heat of thermal conductivity between inner and outer wall of sheath $\varphi_{2}=32.9 \mathrm{~kW}$ 。

$$
\varphi_{2}=2 \pi l \lambda_{1}\left(t_{a}-t_{b}\right) / \ln \left(r_{2}-r_{1}\right)
$$

In the above formula, $t_{\mathrm{a}}, t_{\mathrm{b}}$ are the inner and outer wall temperature of sheath, ${ }^{\circ} \mathrm{C} ; r_{1} 、 r_{2}$ are the inside and outside radius, $\mathrm{m} ; \lambda_{1}$ is thermal conductivity of sheath, $\mathrm{W} /(\mathrm{m} \cdot \mathrm{K})$ 。

The end temperature of the inner wall of the sheath $t_{a}^{\prime}=5.31^{\circ} \mathrm{C}$. consequently, considered the temperature difference in heat transfer, the outlet temperature of the hot air input in the sheath $t_{2} \geq 6^{\circ} \mathrm{C}$ 。

(2) There are three heat transfer processes between the hot air inside the sheath and the outdoor air, namely the turbulent convection heat transfer of the hot air inside the sheath, the thermal conductivity between inner and outer wall of sheath and the force convection heat transfer of cold air across the outer wall of sheath. The total heat transfer coefficient $\mathrm{K}$ is calculated according to the following formula.

$$
\frac{1}{K}=\frac{1}{\alpha_{0}}+\frac{d_{0}}{2 \lambda_{w}} \ln \frac{d_{0}}{d_{i}}+\frac{1}{\alpha_{i}} \frac{d_{0}}{d_{i}}
$$

In the above formula, $K$ is the total heat transfer coefficient, $\mathrm{W} /\left(\mathrm{m}^{2} \cdot \mathrm{K}\right) ; \alpha_{\mathrm{i}} 、 \alpha_{0}$ are the fluid heat transfer efficient of internal and external sheath, $\mathrm{W} /\left(\mathrm{m}^{2} \cdot \mathrm{K}\right)$; $\mathrm{d}_{\mathrm{i}} 、 \mathrm{~d}_{0}$ are the internal and external diameters, $\mathrm{m} ; \lambda_{\mathrm{w}}$ is the thermal conductivity of sheath, $\mathrm{W} /(\mathrm{m} \cdot \mathrm{K}) ; \alpha_{\mathrm{i}} 、 \alpha_{0}$ were calculated as following:

$$
\alpha_{0}=N u_{o} \lambda_{2} / d_{0}, \quad \alpha_{i}=N u_{i} \lambda_{1} / d_{i}
$$

In the above formula, $\mathrm{Nu}_{\mathrm{i}}, \mathrm{Nu}_{\mathrm{o}}$ are the Nusselt number of internal and external fluid.

(3) The heat transfer temperature difference $\Delta t$ between hot air and the outer wall of the sheath is the logarithmic temperature difference.

$$
\Delta t=\left[\left(t_{1}-t_{w}\right)-\left(t_{2}-t_{w}\right)\right] / \ln \left[\frac{t_{1}-t_{w}}{t_{2}-t_{w}}\right]
$$

In the above formula, $t_{1} 、 t_{2}$ are the inlet and outlet temperature of hot air, ${ }^{\circ} \mathrm{C}$; $\mathrm{t}_{\mathrm{w}}$ is the air temperature outside the sheath, ${ }^{\circ} \mathrm{C}$; the value is -3 ; 
(4) The heat exchange between the hot air inside the sheath and the cold air outside the sheath $Q_{1}$ can be converted into function related to $t_{1} 、 t_{2}$ and $R_{e} 、 P_{r}$, namely the equation as following:

$$
Q_{1}=\frac{A\left[\left(t_{1}-t_{w}\right)-\left(t_{2}-t_{w}\right)\right] / \ln \left[\frac{t_{1}-t_{w}}{t_{2}-t_{w}}\right]}{\frac{1}{\left(0.0266 \operatorname{Re}_{o}^{0.805} \operatorname{Pr}_{o}^{1 / 3}\right) \lambda_{2} / d_{0}}+\frac{d_{0}}{2 \lambda_{w}} \ln \frac{d_{0}}{d_{i}}+\frac{1}{\left(0.023 \operatorname{Re}_{i}^{0.8} \operatorname{Pr}_{i}^{0.3}\right) \lambda_{1} / d_{i} d_{i}}}
$$

In the above formula, $\mathrm{Re}_{\mathrm{i}}, \mathrm{Pr}_{\mathrm{i}}$ are the functions of $t_{1} 、 v_{1}$, which are the hot air inlet temperature and velocity. Therefore the $Q_{1}$ can be converted into function of $t_{1}, v_{1}, Q_{1}=f\left(t_{1}, v_{1}\right)$ 。

(5) Based on the principle of energy conservation and the continuity equation, the heat input into the sheath $Q_{2}$ is calculated as follows:

$$
Q_{2}=c_{p 1}\left(\frac{\pi d_{i}^{2}}{4}\right) v_{1} \rho_{1}\left(t_{1}-t_{2}\right)
$$

In the above formula, $\mathrm{c}_{\mathrm{p} 1}$ is specific heat capacity of hot air, $\mathrm{J} /(\mathrm{kg} \cdot \mathrm{K}) ; \rho_{1}$ is density of hot air, $\mathrm{kg} / \mathrm{m}^{3}$ 。The $Q_{2}$ can be converted into the function related to $t_{1}$ 、 $\mathrm{v}_{1}, Q_{2}=g\left(t_{1}, v_{1}\right)$.

\section{Thermodynamic solution of the heat transfer model of the cable sheath}

(1) Under the following assumptions:

considered the ice melt and energy save, the outer wall temperature of the end of the sheath is $t_{b}^{\prime} \geq 3^{\circ} \mathrm{C}$ and outlet temperature of hot air is $6^{\circ} \mathrm{C} \leq \mathrm{t}_{2} \leq 10^{\circ} \mathrm{C}$. Under the premise of ensuring the safety of bridge structure and sheath melting point, $\mathrm{t}_{1} \leq 60^{\circ} \mathrm{C} 、 \mathrm{v}_{1} \leq$ $50 \mathrm{~m} / \mathrm{s}$.

(2) The approximate value of equation $Q_{1}=Q_{2}$ was calculated by the MATLAB compiler in the way of discrete iteration. The unknown value $t_{1} 、 v_{1}$ were dispersed equably within the range of values, $t_{1}=$ [1:1:60], $v_{1}=[1: 1: 50]$. We plug the $t_{1} 、 v_{1}$ into equation $Q_{1}=f\left(t_{1}, v_{1}\right), Q_{2}=g\left(t_{1}, v_{1}\right)$, and calculate in loop iteration solution.

(3) Conditions of solution: when the modulus of $Q_{1}$ and $Q_{2}$ meet the following requirement, which is $\left|Q_{1}-Q_{2}\right| \leq 0.5 \mathrm{~kW}$, we pick up the values of $t_{1} 、 v_{1}$ 、 $Q_{1}(Q)$ as a group of approximate solutions of the equation. The evaluation results are as following.

(4)when $\mathrm{t}_{2}=6^{\circ} \mathrm{C}, 30^{\circ} \mathrm{C} \leq \mathrm{t}_{1} \leq 58^{\circ} \mathrm{C}$,

$34 \mathrm{~m} / \mathrm{s} \leq \mathrm{v}_{1} \leq 50 \mathrm{~m} / \mathrm{s}, 63.62 \mathrm{~kW} \leq \mathrm{Q} \leq 88.93 \mathrm{~kW}$ 。As shown in Fig.1, the points marked in red in the figure are the approximate solution of $Q_{1}=Q_{2}$ with $t_{2}=6^{\circ} \mathrm{C}$.

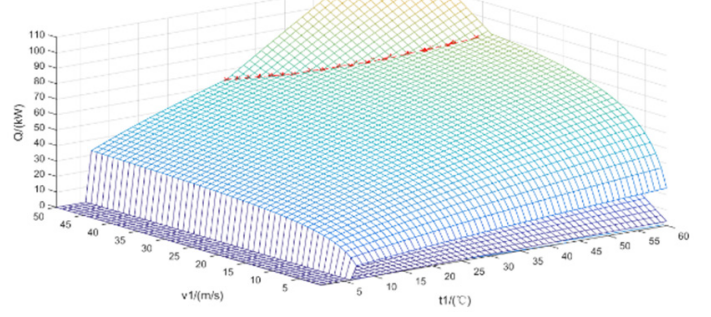

Fig.1. The value of $t_{1} 、 v_{1} 、 Q$ with $t_{2}=6^{\circ} \mathrm{C}$

(5)when $t_{2}=8^{\circ} \mathrm{C}, \quad 41^{\circ} \mathrm{C} \leq t_{1} \leq 60^{\circ} \mathrm{C}$, $38 \mathrm{~m} / \mathrm{s} \leq v_{1} \leq 48 \mathrm{~m} / \mathrm{s}, 81.49 \mathrm{~kW} \leq Q \leq 98.91 \mathrm{~kW}$.As shown in Fig.2, the points marked in red in the figure are the approximate solution of $Q_{1}=Q_{2}$ with $t_{2}=8^{\circ} \mathrm{C}$.

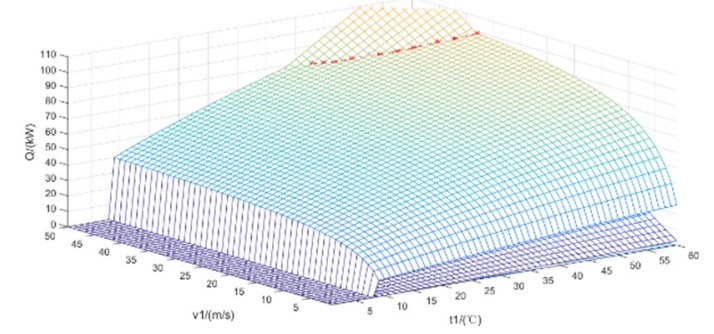

Fig.2. The value of $t_{1} 、 v_{1} 、 Q$ with $t_{2}=8^{\circ} \mathrm{C}$

(6)when $t_{2}=10^{\circ} \mathrm{C}, \quad 47^{\circ} \mathrm{C} \leq t_{1} \leq 60^{\circ} \mathrm{C}$, $43 \mathrm{~m} / \mathrm{s} \leq v_{1} \leq 50 \mathrm{~m} / \mathrm{s}, 94.34 \mathrm{~kW} \leq Q \leq 106.77 \mathrm{~kW}$.As shown in Fig.3, the points marked in red in the figure are the approximate solution of $Q_{1}=Q_{2}$ with $t_{2}=10^{\circ} \mathrm{C}$.

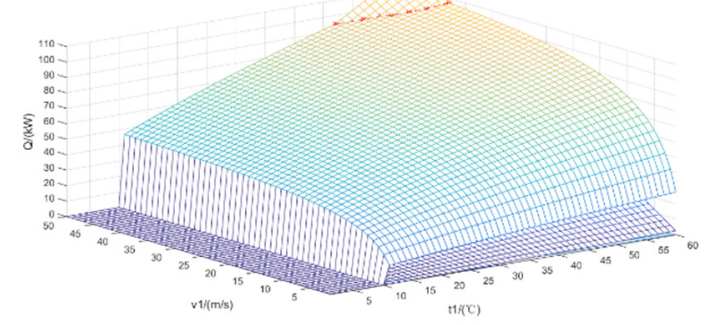

Fig.3. The value of $t_{1}, v_{1}, Q$ with $t_{2}=10^{\circ} \mathrm{C}$

(7)when $6^{\circ} \mathrm{C} \leq t_{2} \leq 10^{\circ} \mathrm{C}$, the value of $t_{1} 、 v_{1} 、 Q$ was shown in Fig.3. The data shown in gray is the design recommendation value in Tab. 3 .

\begin{tabular}{|c|c|c|c|c|c|c|c|c|c|c|c|c|c|c|}
\hline \multicolumn{3}{|c|}{$\mathrm{t}_{2}=6^{\circ} \mathrm{C}$} & \multicolumn{3}{|c|}{$\mathrm{t}_{2}=7^{\circ} \mathrm{C}$} & \multicolumn{3}{|c|}{$\mathrm{t}_{2}=8^{\circ} \mathrm{C}$} & \multicolumn{3}{|c|}{$\mathrm{t}_{2}=9^{\circ} \mathrm{C}$} & \multicolumn{3}{|c|}{$\mathrm{t}_{2}=10^{\circ} \mathrm{C}$} \\
\hline $\mathrm{Q}$ & $\mathrm{t}_{1}$ & $\mathrm{v}_{1}$ & Q & $\mathrm{t}_{1}$ & $\mathrm{v}_{1}$ & $\mathrm{Q}$ & $\mathrm{t}_{1}$ & $\mathrm{v}_{1}$ & $\mathrm{Q}$ & $\mathrm{t}_{1}$ & $\mathrm{v}_{1}$ & $\mathrm{Q}$ & $\mathrm{t}_{1}$ & $\mathrm{v}_{1}$ \\
\hline $\mathrm{kW}$ & ${ }^{\circ} \mathrm{C}$ & $\mathrm{m} / \mathrm{s}$ & $\mathrm{kW}$ & ${ }^{\circ} \mathrm{C}$ & $\mathrm{m} / \mathrm{s}$ & $\mathrm{kW}$ & ${ }^{\circ} \mathrm{C}$ & $\mathrm{m} / \mathrm{s}$ & $\mathrm{kW}$ & ${ }^{\circ} \mathrm{C}$ & $\mathrm{m} / \mathrm{s}$ & $\mathrm{kW}$ & ${ }^{\circ} \mathrm{C}$ & $\mathrm{m} / \mathrm{s}$ \\
\hline 88.93 & 58 & 34 & 93.97 & 59 & 36 & 98.91 & 60 & 38 & 102.05 & 59 & 41 & 106.77 & 60 & 43 \\
\hline 85.51 & 54 & 35 & 91.40 & 56 & 37 & 96.25 & 57 & 39 & 99.25 & 56 & 42 & 103.90 & 57 & 44 \\
\hline 86.46 & 55 & 35 & 88.76 & 53 & 38 & 97.25 & 58 & 39 & 97.44 & 54 & 43 & 102.03 & 55 & 45 \\
\hline 82.94 & 51 & 36 & 87.05 & 51 & 39 & 94.54 & 55 & 40 & 95.58 & 52 & 44 & 100.12 & 53 & 46 \\
\hline 83.91 & 52 & 36 & 84.26 & 48 & 40 & 91.75 & 52 & 41 & 93.68 & 50 & 45 & 99.27 & 52 & 47 \\
\hline 81.28 & 49 & 37 & 85.29 & 49 & 40 & 89.93 & 50 & 42 & 91.73 & 48 & 46 & 97.29 & 50 & 48 \\
\hline 78.57 & 46 & 38 & 82.45 & 46 & 41 & 88.07 & 48 & 43 & 90.85 & 47 & 47 & 94.34 & 47 & 50 \\
\hline
\end{tabular}

Tab.3 The value of $t_{1}, v_{1}, Q$ 


\begin{tabular}{|c|c|c|c|c|c|c|c|c|c|c|c|}
\hline \multirow{2}{*}{$\begin{array}{l}79.57 \\
76.80\end{array}$} & 47 & 38 & 83.49 & 47 & 41 & 87.24 & 47 & 44 & 88.83 & 45 & 48 \\
\hline & 44 & 39 & 81.64 & 45 & 42 & 85.31 & 45 & 45 & 87.91 & 44 & 49 \\
\hline 77.82 & 45 & 39 & 79.75 & 43 & 43 & 83.33 & 43 & 46 & 86.96 & 43 & 50 \\
\hline 74.98 & 42 & 40 & 77.81 & 41 & 44 & 82.42 & 42 & 47 & & & \\
\hline 76.01 & 43 & 40 & 76.92 & 40 & 45 & 81.49 & 41 & 48 & & & \\
\hline 74.17 & 41 & 41 & 76.01 & 39 & 46 & & & & & & \\
\hline 72.27 & 39 & 42 & 73.01 & 36 & 48 & & & & & & \\
\hline 71.40 & 38 & 43 & 72.03 & 35 & 49 & & & & & & \\
\hline 69.43 & 36 & 44 & 71.03 & 34 & 50 & & & & & & \\
\hline 68.51 & 35 & 45 & & & & & & & & & \\
\hline 67.57 & 34 & 46 & & & & & & & & & \\
\hline 66.61 & 33 & 47 & & & & & & & & & \\
\hline 65.64 & 32 & 48 & & & & & & & & & \\
\hline 64.64 & 31 & 49 & & & & & & & & & \\
\hline 03.62 & 30 & 50 & & & & & & & & & \\
\hline
\end{tabular}

When $t_{1}=54^{\circ} \mathrm{C}, v_{1}=35 \mathrm{~m} / \mathrm{s}$, the net area of the

\section{Hydraulic calculation of cable sheath model} sheath $\mathrm{A}=0.032 \mathrm{~m}^{2}$, and the hydraulic calculation of the sheath is shown in Tab.4.

Tab.4 The hydraulic calculation of the sheath

\begin{tabular}{cccccccccccc}
\hline Air quantity & Diameter & $\begin{array}{c}\text { Longth of } \\
\text { sheath }\end{array}$ & $\mathrm{V}$ & $\mathrm{R}$ & $\Delta \mathrm{Py}$ & $\zeta$ & $\begin{array}{c}\text { Dynamic } \\
\text { pressure }\end{array}$ & $\begin{array}{c}\text { Total } \\
\text { resistance }\end{array}$ \\
\hline$(\mathrm{kg} / \mathrm{h})$ & $(\mathrm{mm})$ & $(\mathrm{m})$ & $(\mathrm{m} / \mathrm{s})$ & $(\mathrm{Pa} / \mathrm{m})$ & $(\mathrm{Pa})$ & $(\mathrm{Pa})$ & $(\mathrm{Pa})$ & $(\mathrm{Pa})$ \\
4990 & 205 & 300 & 35.06 & 68.35 & 20503.91 & 2 & 736.18 & 1472.36 & 21976.28 \\
\hline
\end{tabular}

As shown in Tab.4, the frictional resistance $\Delta \mathrm{p}_{\mathrm{y}}=$ $20503.91 \mathrm{~Pa}$, the total resistance $\Delta \mathrm{p}=\Delta \mathrm{p}_{\mathrm{y}}+\Delta \mathrm{p}_{\mathrm{j}}=$ $34436.78 \mathrm{~Pa}$. The pressure value meets the pressure value of PVC material.

\section{Conclusion}

Based on $300 \mathrm{~m}$ of a single sheath the temperature of input hot air supply $t_{1}=54^{\circ} \mathrm{C}$, the supply air speedv $v_{1}=$ $35 \mathrm{~m} / \mathrm{s}$ and $\mathrm{Q}=85.51 \mathrm{~kW}$. The total number of the bridge cables is 264 , the maximum length of a single cable is $300 \mathrm{~m}$, and the minimum length of a single cable is $210 \mathrm{~m}$. To simplify calculation, the cable lengths were all considered as $300 \mathrm{~m}$, so the total heat input into the sheath is $22,574.64 \mathrm{~kW}$.

Based on the establishment of heat transfer model for the cable-stayed bridge's single cable sheath, in order to prevent the cable sheath from freezing in winter under the bad weather, and ensure the temperature of the end of sheath's outwall is more than $3^{\circ} \mathrm{C}$, according to the law of conservation of energy, the range of temperature and speed of input hot air were estimated. The calculation of the model provides a theoretical basis and design reference for the application of hot air to the cable sheath melt system for cable-stayed bridge.

On the premise of keeping the safety of the bridge and maintaining the existing facade, and aiming at the structural characteristics of the existing cable-stayed bridge, the use of the hot air ice melt system of cable sheath for the existing cable-stayed bridge has a reference significance for the application in reconstruction of the existing cable-stayed bridge to prevent freezing.

However, the huge energy consumption demand, the choice of heat source and equipment installation are all chnical difficulties, the design scheme become used still need to be further demonstrated, Such as the relief valve is added to both ends of the sheath, which can not only guarantee the hot air not to lose instantly, reduce energy consumption, but also ensure the pressure relief timely when the pressure reaches a certain value.

\section{References}

1. China Railway Bridge Scientific Research Institute Co., LTD. A system and Method of cable deicing and anti-icing for cable-stayed bridge: China, 201810141060[P].2018-08-17

2. China Railway Bridge Scientific Research Institute Co., LTD. A system and method of intelligent dehumidification and deicing for cable-stayed bridge: China, 201810073182[P].2018-07-20

3. China Railway Bridge Scientific Research Institute Co., LTD. A device of deicing and snow removal for cable-stayed bridge: China, 201810140798[P].2018.08.10

4. Zhang ximing, Ren zepei. Heat transfer theory[M].4 versions. Beijing:China building industry press:2001:4-5 